\title{
Clinical utility of cardiac innervation imaging in patients with heart failure
}

\author{
Jeroen J. Bax, MD, PhD \\ a Department of Cardiology, Leiden University Medical Center, Leiden, The Netherlands
}

Received Jun 28, 2017; accepted Jun 28, 2017

doi:10.1007/s12350-017-0988-7

\section{WHAT IS THE PROBLEM?}

Sudden cardiac death is an important problem in clinical cardiology. In the USA; the annual incidence of sudden cardiac death is estimated at 110.8 individuals per 100,000 population per year. ${ }^{1}$ In the year 2015 , it was estimated that 356,461 patients died suddenly of underlying cardiac disease. ${ }^{1}$ Moreover, in patients with successful resuscitation, the recurrence rate of sudden death is high.

Particularly, patients with previous myocardial infarction and reduced left ventricular (LV) function are at elevated risk of sudden death. ${ }^{2}$ With the introduction of the implantable cardioverter defibrillator (ICD), a therapy has become available that has been demonstrated to prevent sudden cardiac death in patients with ischemic and non-ischemic cardiomyopathy.

In the Multicenter Automatic Defibrillator Implantation Trial-I (MADIT-I) study, 196 patients with a history of myocardial infarction ( $\geq 3$ weeks), reduced LV function (LVEF $\leq 35 \%)$ and documented episode of ventricular tachyarrhythmias, were randomized to either prophylactic ICD implantation $(\mathrm{n}=95)$ or standard medical therapy $(\mathrm{n}=101) .^{2}$ Over a 27 -month follow-up period, 15 patients $(15.8 \%$; 11 cardiac death) died in the defibrillator group as compared to 39 patients $(38.2 \%$; 27 cardiac death) in the medical group (hazard ratio for overall mortality, $0.46 ; 95 \%$ confidence interval, 0.26 to $0.82 ; P=0.009)$. Importantly, the use of amiodarone or beta-blockers did not influence these observations.

In a subsequent study (MADIT-II), 1232 patients with previous infarction ( $\geq 1$ month) and LVEF $\leq 30 \%$ were randomized in a $3: 2$ ratio to receive an ICD or medical therapy. ${ }^{3}$ During a 20 -month follow-up period,

\footnotetext{
Reprint requests: Jeroen J. Bax, MD, PhD, Department of Cardiology, Leiden University Medical Center, Leiden, The Netherlands; j.j.bax@lumc.nl

J Nucl Cardiol 2017;24:1594-7.

$1071-3581 / \$ 34.00$

Copyright (C) 2017 American Society of Nuclear Cardiology.
}

mortality was $19.8 \%$ in the patients receiving medical therapy versus $14.2 \%$ in patients receiving an ICD (hazard ratio for the risk of all-cause mortality, 0.69 (95\% confidence interval, 0.51 to $0.93 ; P=0.016$ ). Importantly, age, gender, LVEF, New York Heart Association class, and QRS duration did not influence the results.

Both these studies paved the way for the European Society of Cardiology (ESC) to indicate in their 2015 guidelines that an ICD is indicated in patients with symptomatic heart failure (NYHA class II-III) and reduced LVEF $(\leq 35 \%)^{4}$ (class IA in ischemic heart disease, and class IB in non-ischemic cardiomyopathy). Similar recommendations have been issued by the ACC/ AHA guidelines. 5

It has also become evident from the MADIT-II trial that a limited number of patients received appropriate ICD therapy during an average of 21 months of followup. ${ }^{6}$ More specifically, of the 720 patients receiving an ICD in the MADIT-II trial, 169 (23.5\%) patients received antiarrhythmic therapy(anti-tachycardia pacing in 139 patients, and defibrillator shocks in 30) and 551 (76.5\%) patients did not receive ICD therapy.

More recently, Kober et al. ${ }^{7}$ demonstrated that in patients with non-ischemic cardiomyopathy, prophylactic ICD implantation did not improve long-term outcome as compared to usual clinical care. Specifically, 1116 patients with non-ischemic cardiomyopathy (LVEF $\leq 35 \%$ ) were randomized to ICD implantation $(\mathrm{n}=556)$ or usual care $(\mathrm{n}=560)$; all-cause death was $21.6 \%$ in the ICD group versus $23.4 \%$ in the control group (hazard ratio, $0.87 ; 95 \%$ confidence interval $[\mathrm{CI}], 0.68$ to $1.12 ; P=0.28)$. Still, sudden cardiac death was more frequent in the usual care group $(8.2 \%)$ versus the ICD group (4.3\%) (hazard ratio, $0.50 ; 95 \% \mathrm{CI}, 0.31$ to $0.82 ; P=0.005)$.

Moreover, ICD implantation is associated with procedural complications, device/lead infections, and inappropriate shocks. ${ }^{8}$ Thus, there is significant benefit from ICDs to prevent sudden cardiac death, but the criterium of LVEF $\leq 35 \%$ may be suboptimal for 
selecting the patients who may benefit most from ICD implantation, and a more personalized risk stratification may be of potential use. ${ }^{9}$

Various ECG-based criteria have been proposed, including microvolt $\mathrm{T}$-wave alternans, signal-averaged ECG, QRS fragmentation, and various measures of autonomic (dys-)function such as heart rate variability. ${ }^{10}$ In addition, different imaging techniques have attempted to better identify the substrate underlying sudden cardiac death, specifically advanced echocardiographic and CMR techniques, as well as nuclear imaging with PET and SPECT. The different imaging techniques reflect different aspects of the LV substrate underlying the lethal ventricular arrhythmias; the anatomical substrate is probably the presence of central homogenous scar tissue (secondary to myocardial infarction), with a peripheral, heterogeneous border zone with fibrosis, viable but jeopardized myocardium and normal tissue. Contrastenhanced CMR is focused on anatomical imaging (specifically scar and fibrosis assessment), whereas echocardiography with strain reflects functional imaging (LV deformation assessment) and nuclear imaging with PET and SPECT addresses biological imaging (specifically innervation and denervation assessment). ${ }^{9}$ Over the recent years, the use of cardiac innervation imaging with 123I-metaiodobenzylguanidine (MIBG) and planar imaging or SPECT has been evaluated for risk stratification of heart failure patients at risk of sudden cardiac death. In the current issue of the Journal, two articles are published regarding the pros and cons of MIBG imaging, mostly focusing on risk stratification in patients with heart failure and elevated risk of sudden cardiac death. $^{11,12}$

\section{MIBG FOR RISK STRATIFICATION: THE EVIDENCE OF NEURO-CARDIAC IMAGING}

The first article, by Travin, addresses the pros of MIBG imaging. ${ }^{11} \mathrm{He}$ introduces the concept of the heartto-mediastinum $(\mathrm{H} / \mathrm{M})$ ratio to quantify the tracer uptake in the heart as compared to the mediastinum on planar images, reflecting cardiac innervation and denervation. Many smaller studies have used this parameter to demonstrate the use of MIBG for risk stratification of heart failure patients. Agostini and colleagues ${ }^{13}$ performed a large analysis including 290 heart failure patients who previously underwent MIBG imaging (between 1993 and 2002). During a 2-year follow-up, 67 patients (26\%) experienced a major cardiac event (death, cardiac transplantation, potentially lethal arrhythmias). These patients had a lower $\mathrm{H} / \mathrm{M}$ ratio $(1.51 \pm 0.30)$ as compared with the patients without events $(1.97 \pm 0.54, P<0.001)$.

Dr Travin then referred to the ADMIRE-HF (AdreView Myocardial Imaging for Risk Evaluation in Heart
Failure) trial and its sub-studies. ${ }^{14}$ The ADMIRE-HF study included 961 heart failure patients (NYHA II-III) and $\mathrm{LVEF} \leq 35 \%$ who underwent MIBG imaging, and the $\mathrm{H} / \mathrm{M}$ ratio was assessed from the 4-hour delayed image; a value of 1.60 was used as the normal value. Patients were followed up for 2 years and the end-points included time to first occurrence of NYHA functional class progression, potentially life-threatening arrhythmic event, or cardiac death. During a median follow-up, 237 patients $(25 \%)$ experienced events; the 2-year event rate was $15 \%$ for $\mathrm{H} / \mathrm{M} \geq 1.60$ and $37 \%$ for $\mathrm{H} / \mathrm{M}<1.60$, and the $\mathrm{H} / \mathrm{M}$ ratio was predictive of all end-points. On multivariate analysis, $\mathrm{H} / \mathrm{M}$ ratio, LVEF, B-type natriuretic peptide, and NYHA class were predictive of outcome. Addition of the $\mathrm{H} / \mathrm{M}$ ratio enabled further stratification in patients with high B-type natriuretic peptide (140 ng/l) and low LVEF ( $\leq 30 \%)$.

More recently, a pooled analysis from Japan was reported, including 6 cohorts with 1322 heart failure patients, with a follow-up of 78 months, and primary outcome being all-cause mortality. ${ }^{15}$ The mortality was $5.6 \%$ at 1 year, and $19.7 \%$ at 5-year follow-up. On the multivariate analysis, age, NYHA class, LVEF and the late $\mathrm{MIBG} \mathrm{H} / \mathrm{M}$ ratio were predictive of outcome.

All these data have built a strong case supporting the use of MIBG for risk stratification in heart failure patients, and have shown the incremental value of the $\mathrm{H} / \mathrm{M}$ ratio over the routine risk markers. One important issue is the predictive value. This remains to be further explored in future studies. As with any technique, a high negative predictive value is important: "to rule out.", This could imply not providing a certain therapy or less close monitoring. In the ADMIRE-HF study, the allcause mortality was $1 \%$ (2 patients of 201) in the patients with an $\mathrm{H} / \mathrm{M}$ ratio $\geq 1.6$. Moreover, in the highrisk groups (according to BNP $>140 \mathrm{ng} / \mathrm{l}$ and LVEF $\leq 30 \%$ ) with a $\mathrm{H} / \mathrm{M}$ ratio $\geq 1.6$ there were no cardiac deaths. These data are supportive of the conception that MIBG imaging could serve as gate-keeper for ICD implantation.

\section{WHAT ARE THE UNCERTAINTIES}

Drs Liga and Scholte discuss the limitations of MIBG imaging hampering the widespread acceptance of this technique in clinical practice. ${ }^{12}$ The first issue discussed by these authors concerns the need for a standardized protocol. The main parameter used in the clinical setting is the $\mathrm{H} / \mathrm{M}$ ratio, which reflects cardiac innervation and denervation. At present, an early (15 min after tracer injection) and late MIBG scan (4 hour after tracer injection) are obtained, and the H/M ratio can be derived from both scans. It is currently not clear which scan provides the optimal prognostic 
information. From a practical point of view, it would be ideal to use the scan obtained within the first hour after tracer injection. Finally, the cut-off value of 1.6 needs further, prospective evaluation.

Other parameters from planar MIBG imaging have also been used, such as the washout rate, and these are less well validated as compared to the $\mathrm{H} / \mathrm{M}$ ratio.

Moreover, with planar imaging, the global sympathetic innervation of the heart can be evaluated, but regional information may be more important. SPECT provides information on regional variations in sympathetic innervation, but regional physiological variations also occur, with less tracer uptake in the inferior wall in normal individuals. Also, in patients with severe heart failure, tracer uptake may be low resulting in poor SPECT image quality, and in general, data acquisition with SPECT is more time-consuming than planar imaging.

\section{WHAT EVIDENCE IS MISSING AND NEEDED?}

Prospective, randomized controlled trials will be needed to establish the role of MIBG in risk stratification of heart failure patients. From a clinical point of view, the ADMIRE-HF study provided strong prognostic data in a prospective cohort of heart failure patients, but an important question remains whether MIBG could direct therapy in these patients and specifically guide ICD implantation. As outlined above, the current selection criterium of LVEF $\leq 35 \%$ does not optimally include and exclude patients who need an ICD for primary prevention in ischemic and non-ischemic cardiomyopathy. As Dr Travin points out, this trial is planned, including $>2,000$ heart failure patients (LVEF between $30 \%$ and $35 \%$, and NYHA class II-III) who will receive MIBG-guided ICD implantation or guidelinedirected ICD implantation; this trial will compare the outcomes (primary outcome all-cause mortality) over 2.75 to 3 years, but will only be completed in $2019 .{ }^{16}$ However, Dr Travin also points out, this trial will take time to be completed, but there is currently significant evidence that MIBG contributes to risk stratification in heart failure patients, probably more evidence than has been obtained with other imaging techniques that are used in clinical practice.

\section{Disclosure}

The department of Cardiology, Leiden University Medical Center, The Netherlands, has received unrestricted research grants of Medtronic, Biotronik, Boston Scientific and Edwards Lifesciences.

\section{References}

1. Mozaffarian D, Benjamin EJ, Go AS, Arnett DK, Blaha MJ, Cushman M, Das SR, de Ferranti S, Després JP, Fullerton HJ, Howard VJ, Huffman MD, Isasi CR, Jiménez MC, Judd SE, Kissela BM, Lichtman JH, Lisabeth LD, Liu S, Mackey RH, Magid DJ, McGuire DK, Mohler ER, Moy CS, Muntner P, Mussolino ME, Nasir K, Neumar RW, Nichol G, Palaniappan L, Pandey DK, Reeves MJ, Rodriguez CJ, Rosamond W, Sorlie PD, Stein J, Towfighi A, Turan TN, Virani SS, Woo D, Yeh RW, Turner MB. American Heart Association Statistics Committee; Stroke Statistics Subcommittee. Heart Disease and Stroke Statistics-2016 Update: A Report From the American Heart Association. Circulation 2016;26:e38-360.

2. Moss AJ, Hall WJ, Cannom DS, Daubert JP, Higgins SL, Klein H, Levine JH, Saksena S, Waldo AL, Wilber D, Brown MW, Heo M, Multicenter Automatic Defibrillator Implantation Trial Investigators. Improved survival with an implanted defibrillator in patients with coronary disease at high risk for ventricular arrhythmia. N Engl J Med 1996;335:1933-40.

3. Moss AJ, Zareba W, Hall WJ, Klein H, Wilber DJ, Cannom DS, Daubert JP, Higgins SL, Brown MW, Andrews ML. Prophylactic implantation of a defibrillator in patients with myocardial infarction and reduced ejection fraction. Multicenter Automatic Defibrillator Implantation Trial II Investigators. N Engl J Med 2002;346:877-83

4. Priori SG, Blomström-Lundqvist C, Mazzanti A, Blom N, Borggrefe M, Camm J, Elliott PM, Fitzsimons D, Hatala R, Hindricks G, Kirchhof P, Kjeldsen K, Kuck KH, Hernandez-Madrid A, Nikolaou N, Norekvål TM, Spaulding C, Van Veldhuisen DJ. 2015 ESC Guidelines for the management of patients with ventricular arrhythmias and the prevention of sudden cardiac death: The Task Force for the Management of Patients with Ventricular Arrhythmias and the Prevention of Sudden Cardiac Death of the European Society of Cardiology (ESC). Endorsed by: Association for European Paediatric and Congenital Cardiology (AEPC). Eur Heart J 2015;36:2793-867.

5. Yancy CW, Jessup M, Bozkurt B, Butler J, Casey DE Jr, Drazner MH, Fonarow GC, Geraci SA, Horwich T, Januzzi JL, Johnson MR, Kasper EK, Levy WC, Masoudi FA, McBride PE, McMurray JJ, Mitchell JE, Peterson PN, Riegel B, Sam F, Stevenson LW, Tang WH, Tsai EJ, Wilkoff BL. 2013 ACCF/AHA guideline for the management of heart failure: Executive summary: A report of the American College of Cardiology Foundation/American Heart Association Task Force on practice guidelines. Circulation 2013;128:1810-52.

6. Moss AJ, Greenberg H, Case RB, Zareba W, Hall WJ, Brown MW, Daubert JP, McNitt S, Andrews ML, Elkin AD, Multicenter Automatic Defibrillator Implantation Trial-II (MADIT-II) Research Group. Long-term clinical course of patients after termination of ventricular tachyarrhythmia by an implanted defibrillator. Circulation 2004;110:3760-65.

7. Køber L, Thune JJ, Nielsen JC, Haarbo J, Videbæk L, Korup E, Jensen G, Hildebrandt P, Steffensen FH, Bruun NE, Eiskjær H, Brandes A, Thøgersen AM, Gustafsson F, Egstrup K, Videbæk R, Hassager C, Svendsen JH, Høfsten DE, Torp-Pedersen C, Pehrson $\mathrm{S}$, DANISH Investigators. Defibrillator implantation in patients with nonischemic systolic heart failure. $N$ Engl $J$ Med 2016;375:1221-30.

8. Van der Bijl P, Delgado V, Bax JJ. Noninvasive imaging markers associated with sudden cardiac death. Trends Cardiovasc Med 2016;26:348-60. 
9. Bertini M, Schalij MJ, Bax JJ, Delgado V. Emerging role of multimodality imaging to evaluate patients at risk for sudden cardiac death. Circ Cardiovasc Imaging 2012;5:525-35.

10. McElwee SK, Velasco A, Doppalapudi H. Mechanisms of sudden cardiac death. J Nucl Cardiol 2016;23:1368-79.

11. Travin MI. Neurocardiac imaging has a proven value in patient management. J Nucl Cardiol 2017. doi:10.1007/s12350-017-0948-2.

12. Liga R, Scholte AJHA. Neuro-cardiac imaging has a proven value in patient management: Con. J Nucl Cardiol 2017. doi: 10.1007/s12350-017-0947-3.

13. Agostini D, Verberne HJ, Burchert W, Knuuti J, Povinec P, Sambuceti G, Unlu M, Estorch M, Banerjee G, Jacobson AF. I-123-mIBG myocardial imaging for assessment of risk for a major cardiac event in heart failure patients: Insights from a retrospective European multicenter study. Eur J Nucl Med Mol Imaging 2008;35:535-46.

14. Jacobson AF, Senior R, Cerqueira MD, Wong ND, Thomas GS, Lopez VA, Agostini D, Weiland F, Chandna H, Narula J,
ADMIRE-HF Investigators. Myocardial iodine-123 metaiodobenzylguanidine imaging and cardiac events in heart failure. Results of the prospective ADMIRE-HF (AdreView Myocardial Imaging for Risk Evaluation in Heart Failure) study. J Am Coll Cardiol 2010;55:2212-21.

15. Nakata T, Nakajima K, Yamashina S, Yamada T, Momose M, Kasama S, Matsui T, Matsuo S, Travin MI, Jacobson AF. A pooled analysis of multicenter cohort studies of (123)I-mIBG imaging of sympathetic innervation for assessment of long-term prognosis in heart failure. JACC Cardiovasc Imaging 2013;6:77284.

16. International study to determine if AdreView heart function scan can be used to identify patients with mild or moderate heart failure (HF) that benefit from implanted medical device, ADMIRE ICD, at Clin trials: https://www.clinicaltrials.gov/ct2/show/NCT02656 329, Accessed June 28, 2017. 